Article

\title{
3D Finite Element Model for Writing Long-Period Fiber Gratings by $\mathrm{CO}_{2}$ Laser Radiation
}

\author{
João M. P. Coelho ${ }^{1,2, *}$, Marta Nespereira ${ }^{1}$, Manuel Abreu ${ }^{1}$ and José Rebordão ${ }^{1}$ \\ 1 Laboratory of Optics, Lasers and Systems, Faculty of Sciences, University of Lisbon, \\ Campus do Lumiar, Estrada do Paço do Lumiar, 22, Building D, 1649-038 Lisboa, Portugal; \\ E-Mails: mcnespereira@fc.ul.pt (M.N.); maabreu@fc.ul.pt (M.A.); jmrebordao@fc.ul.pt (J.R.) \\ 2 Institute of Biophysics and Biomedical Engineering, Faculty of Sciences, University of Lisbon, \\ Faculdade de Ciências da Universidade de Lisboa, Campo Grande, Lisboa 1749-016, Portugal \\ * Author to whom correspondence should be addressed; E-Mail: joao.coelho@ fc.ul.pt; \\ Tel.: +351-217-500-759; Fax: +351-217-163-048.
}

Received: 1 July 2013; in revised form: 6 August 2013 / Accepted: 8 August 2013 / Published: 12 August 2013

\begin{abstract}
In the last years, mid-infrared radiation emitted by $\mathrm{CO}_{2}$ lasers has become increasing popular as a tool in the development of long-period fiber gratings. However, although the development and characterization of the resulting sensing devices have progressed quickly, further research is still necessary to consolidate functional models, especially regarding the interaction between laser radiation and the fiber's material. In this paper, a 3D finite element model is presented to simulate the interaction between laser radiation and an optical fiber and to determine the resulting refractive index change. Dependence with temperature of the main parameters of the optical fiber materials (with special focus on the absorption of incident laser radiation) is considered, as well as convection and radiation losses. Thermal and residual stress analyses are made for a standard single mode fiber, and experimental results are presented.
\end{abstract}

Keywords: laser processing; long-period fiber gratings; finite element modeling; fiber-based sensors; refractive-index modulation; thermo-mechanical processes 


\section{Introduction}

Long-period fiber grating, or LPFG, play an important role in the development of fiber-based sensors in several areas of engineering. In the field of sensing systems, they are well suited to measure mechanical quantities: they can be applied as structural bend sensors, temperature sensors, axial strain sensors, refractive index sensors and biochemical optical sensors [1-7].

A LPFG can be considered a particular type of Fiber Bragg Grating, or FBG, in which the period of the index modulation, $\Lambda$, satisfies a phase matching condition between the fundamental core mode and a forward propagating cladding mode. This condition relates the resonant wavelength of the light into a particular cladding mode $m, \lambda^{\mathrm{m}}$ res, the effective refractive index of the core, $n_{\text {eff,co }}$, and the effective refractive indexes of the $m$ th-cladding mode, $n^{m}{ }_{\text {eff,cl }}$

$$
\lambda_{\text {res }}^{m}=\left(n_{\text {eff }, c o}-n_{\text {eff }, c l}^{m}\right) \Lambda
$$

These grating-based devices are produced by periodically creating a perturbation of the refractive indexes of the core and/or cladding along the length of the fiber. Typically the length of a FBG ranges from a few millimeters to about one centimeter, with modulation periods of a few dozens of microns. The length of a LPFG is of the order of a few centimeters with periods of hundreds of micrometers. LPFGs require therefore simpler fabrication processes and have lower costs, and show lower retro-reflection, higher sensitivity and robustness in sensing applications when compared with FBG [8].

A LPFG can be produced mechanically [9], chemically (etching) [10], by photonic processes (ultra-violet irradiation) [11] or thermally, either by applying an electric arc discharge [12] or a mid-infrared radiation (MIR) laser source [13,14]. Within the family of thermal techniques, MIR from $\mathrm{CO}_{2}$ lasers has guaranteed better predictability and repeatability [15].

Since the first reports by Davis et al. [13] and Akiyama et al. [14] on the use of a $10.6 \mu \mathrm{m}$ wavelength laser beam emitted by a $\mathrm{CO}_{2}$ laser, different experimental methodologies have been used to write LPFGs [15]. The most common is, probably, using a static asymmetrical irradiation with a $\mathrm{CW}_{2} \mathrm{CO}_{2}$ laser and a cylindrical lens focusing a laser line on the fiber. This method has the advantage of requiring a simpler setup and, although the irradiation occurs on just one of the sides of the fiber, the line-shaped beam reduces the writing asymmetric effect when compared with focused circular laser beams.

In parallel to the development of writing techniques, research on the physical mechanisms responsible by refractive index changes has progressed. Based on several experimental analysis, most of the existing work has considered that the main mechanism responsible for inducing a refractive-index change is the relaxation of internal stresses by the exposure to the laser radiation [16-21]. Taking this in consideration, several analytical models were developed, based mainly on solutions of the general heat conduction equation [22,23]. These models, although giving proven data on the necessary engineering parameters, are based on expressions that do not consider all the physical phenomena (e.g., convection losses) and assume several simplifications (e.g., they ignore the temperature dependence of glass parameters).

In the following sections, the different thermo-mechanical effects of the interaction between a MIR laser beam and a standard silica-based single mode optical fiber will be analyzed, both theoretically and experimentally, and a 3D finite element method (FEM) model, implemented in the COMSOL 
Multiphysics program, is described, considering temperature dependence of the main parameters, in particular the absorption of laser radiation by the fiber's material.

\section{Thermo-Mechanical Model}

Considering a silica-based single mode optical fiber under tension irradiated by an elliptical $10.6 \mu \mathrm{m}$ wavelength $\mathrm{CO}_{2}$ laser beam (Figure 1), two main phenomena must be considered: the thermal heating due to the interaction between the photons and the glass molecular structure and the stress due to the differences between a relatively low-viscosity doped silica core and a relatively high-viscosity pure silica cladding [16].

Figure 1. Schematics of (a) coordinates used in this work and (b) main physical interfaces.

The origin of the reference system is in the middle of the laser line.

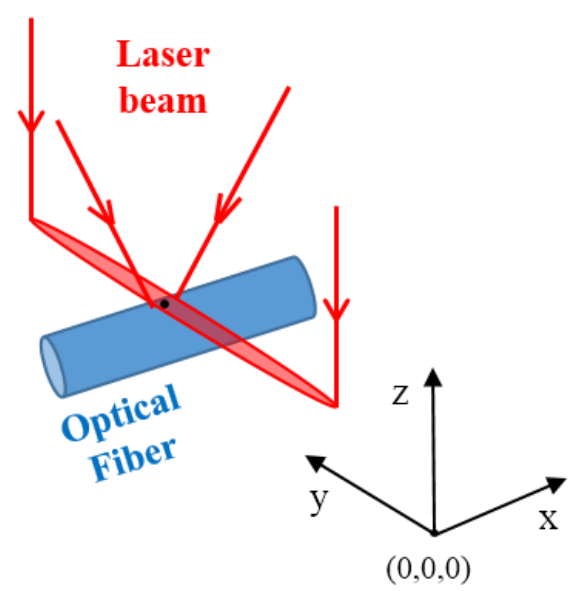

(a)

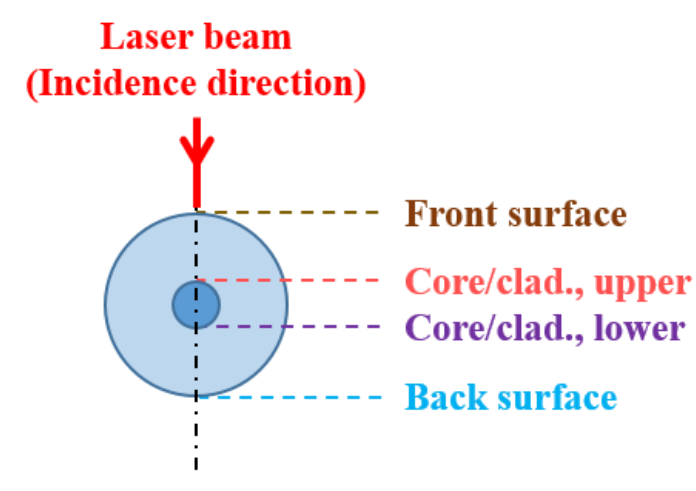

(b)

Differences between core and cladding thermal expansion coefficients and viscosity lead to residual thermal stresses and draw-induced residual stresses. In the case under study, these localized effects periodically induced along the fiber's length, can be responsible for the creation of the gratings. This effect is due to the refractive index change resulting from frozen-in viscoelasticity [17].

\subsection{Theory}

The refractive index change in a silica-based optical fiber can be approximated by the relation [17]:

$$
\Delta n(T) \approx-6.35 \times 10^{-6} \sigma(T)
$$

where $\sigma(T)$ represents the overall (both thermal, $\sigma_{T}(T)$, and drawn-induced, $\sigma_{x}$ ) residual stresses (in MPa) in the fiber's axial direction. According to Yablon [16], stresses in the other directions can be neglected.

The fiber is composed of a low viscosity, high thermal expansion coefficient core and a high viscosity, low thermal expansion coefficient cladding, the drawn-induced axial residual stresses act in opposition to the residual thermal stress. Either one can prevail or both can compensate each other. 
The temperature distribution around a heat source can be obtained by solving the heat conduction problem. In what concerns the temperature variation with time, $t$, (transient regime) due to the action of a heat source $Q(x, y, z, t)$, the resulting energy balance leads to the heat conduction equation:

$$
\left\{\frac{\partial \rho}{\partial t}+\nabla \cdot(\rho \vec{v})\right\} \int C p d T+\rho C p\left(\frac{\partial T}{\partial t}+\vec{v} \cdot \nabla T\right)=\nabla \cdot K \nabla T+q(T)+Q(x, y, z, t)
$$

being $\vec{v}$ the velocity vector, $\rho$ the density, $C p$ the specific heat, and $K$ the thermal conductivity, these are the main parameters of the heated material. The factor $q(T)$ quantifies the convective and radiative heat flux [22]:

$$
q(T)=h\left(T_{\mathrm{inf}}-T\right)+\varepsilon \sigma_{B}\left(T_{a m b}{ }^{4}-T^{4}\right)
$$

being $T_{i n f}$ the external temperature, $T_{a m b}$ the environment temperature, $h$ the heat transfer coefficient, $\sigma_{B}$ the Stefan-Boltzmann constant and $\varepsilon$ the surface emissivity.

When considering the condition of mass conservation, an isotropic material with $K=K(T)$, and introducing the thermal diffusivity $k$, given by $K /(\rho C p)$, Equation (3) can be simplified to:

$$
\frac{\partial T}{\partial t}+\vec{v} \cdot \nabla T-k(\nabla \cdot \nabla T)+q(T)=\frac{Q(x, y, z, t)}{\rho C_{p}}
$$

The power generation per unit volume of the material is given by $Q(x, y, z, t)$ and depends on the characteristics of the heat source. For a laser beam incident on a surface and propagating in the z direction:

$$
Q(x, y, z, t)=a_{T} \cdot(1-R) I(x, y, z) g(t)
$$

where $a_{T}$ is the attenuation coefficient of the material, $R$ its reflectance and $I(r, t)$ the irradiance. For continuous wave emission with a duration $\tau$ :

$$
g(t)=\left\{\begin{array}{c}
0, \text { if } t \leq 0 \vee t>\tau \\
I(x, y, z), \text { if } 0<t \leq \tau
\end{array}\right.
$$

If the laser beam has an elliptical Gaussian distribution (at the surface being irradiated), then [24]:

$$
I(x, y, z)=\frac{8 a_{T} P}{\pi d_{x} d_{y}} \exp \left[-2\left(\frac{x^{2}}{d_{x}^{2}}+\frac{y^{2}}{d_{y}^{2}}\right)\right] \cdot \exp \left(-a_{T} z\right)
$$

where $d_{\mathrm{x}}$ and $d_{\mathrm{y}}$ are the dimensions of the ellipse's axis.

Solving Equation (5), the thermally-induced residual stresses, $\sigma(T)$, can be obtained considering the constitutive equations for a linear isotropic thermoelastic material and the stress tensor obtained [25].

The residual axial elastic stresses in the cladding and core, $\sigma_{c l}$ and $\sigma_{c o}$, respectively, resulting from a draw tension $F$, over the equivalent cross-sectional areas $A_{c l}$ and $A_{c o}$ can be obtained from [26]:

$$
\sigma_{x, c l}=\frac{F}{A_{c l}}\left(\frac{A_{c o} E_{c o}}{A_{c o} E_{c o}+A_{c l} E_{c l}}\right)
$$

and: 


$$
\sigma_{x, c o}=F\left(\frac{E_{c o}}{A_{c o} E_{c o}+A_{c l} E_{c l}}\right)
$$

Besides stress-related refractive index change, localized heating can induce micro-deformation of the fiber and changes in the glass structure. The latter is likely to occur in the core for which the fictive temperature (glass structure doesn't change below the fictive temperature) is lower [18,27]. As reported, (e.g., [18]) for a Ge-doped core the fictive temperature ranges from 1,150 K to 1,500 K.

\subsection{Physical Parameters}

The optical fiber is a Corning SMF-28 fiber $(125 \mu \mathrm{m}$ diameter pure fused silica cladding and $8.2 \mu \mathrm{m}$ diameter core of $3.5 \mathrm{~mol} \% \mathrm{Ge}$-doped $\mathrm{SiO}_{2}$ ) [28]. Figures $2-4$ show the change on the different parameters with temperature. For some parameters (shown in Figure 2), the temperature dependence was modelled using native COMSOL functions for a Corning fused silica glass (7940). The doping effect on most of the parameters was disregarded mainly because the Ge concentration in the fiber's core is very low [29]. However, for the Young's modulus and Poisson's ratio (Figure 3), we extrapolated the function behavior [30]. Furthermore, the heat transfer coefficient was considered $h=418.68 \mathrm{~W} \cdot \mathrm{m}^{-2} \cdot \mathrm{K}^{-1}[22]$ and $R=0.15[31]$.

Figure 2. Variation of the main parameters used of Corning 7940 fused silica glass as defined in the COMSOL's materials library.
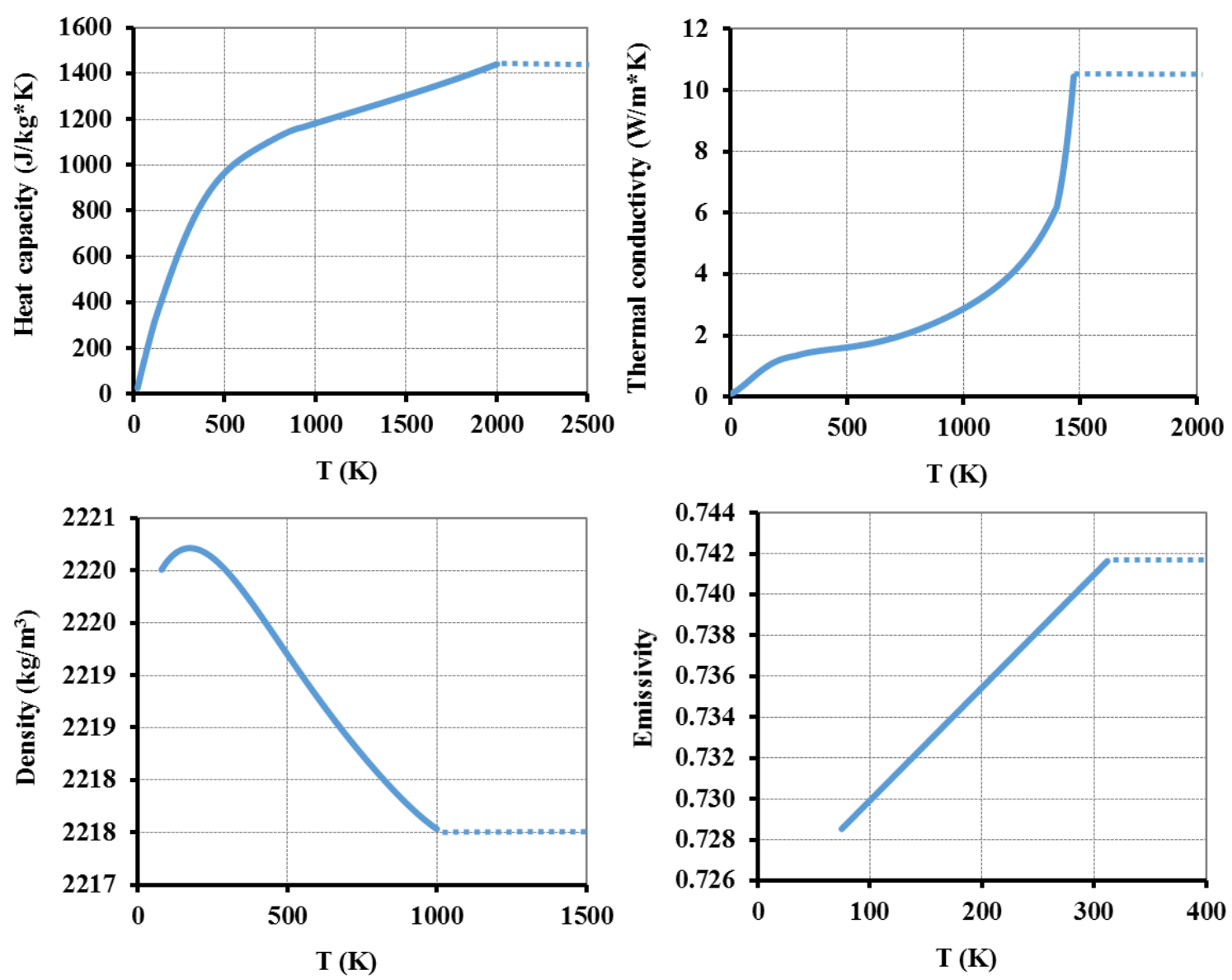
Figure 3. Variation of Young's module and Poisson's ratio for both fused silica (from COMSOL materials library) cladding and Ge-doped fused silica (extrapolated) core glasses.
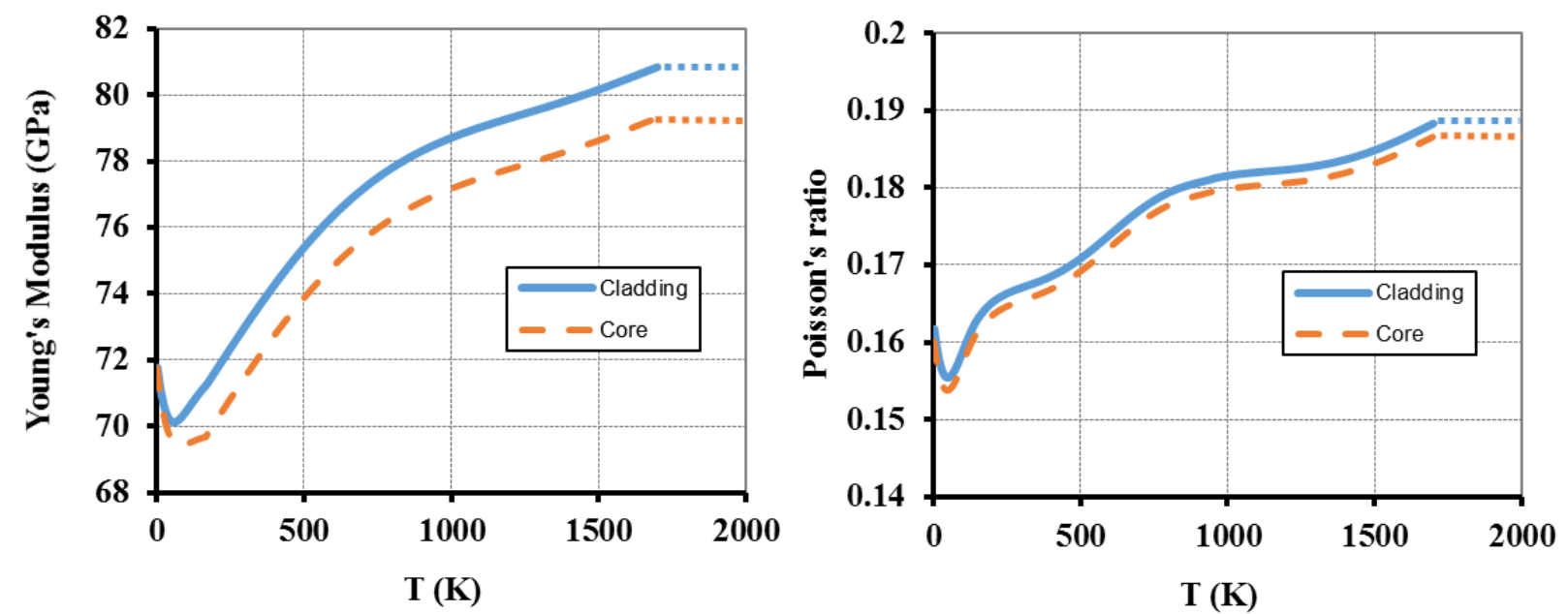

Figure 4. Absorption coefficient variation with temperature for fused silica glass accordingly with Equation (11).

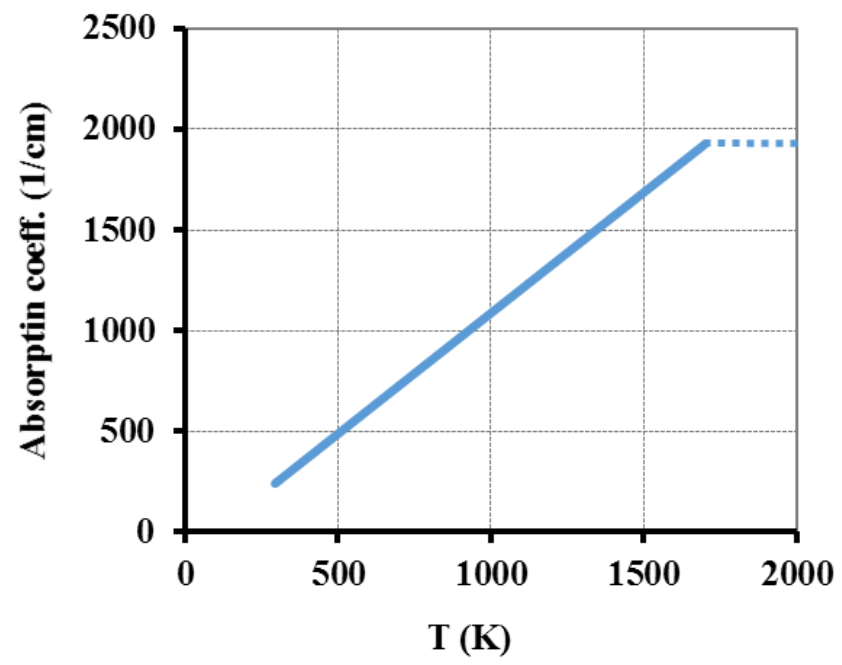

Another factor to take in consideration is the material's absorption coefficient for the wavelength of interest. Accordingly with Tian [32] the absorption coefficient of fused silica, $a_{T}$, for $10.59 \mu \mathrm{m}$ for $\mathrm{CO}_{2}$ laser wavelength $\left(\lambda_{1}\right)$, within $298 \mathrm{~K}-2,073 \mathrm{~K}$ temperature range can be obtained by:

$$
a_{T}(T)=\frac{4 \pi}{\lambda_{1}}\left[1.82 \times 10^{-2}-10.1 \times 10^{-5} \times(T-273)\right]
$$

This equation was used and the corresponding curve is presented in Figure 4. In the plots presented in Figures 2-4, the dotted lines represent the constant value that is assumed for higher temperature ranges.

\subsection{Implementation}

The physical problem was mathematically solved using the FEM model implemented using the COMSOL Multiphysics 3.5 program to create the transient heat conduction and (mechanical) stress-strain models under the conditions of this study. In order to introduce some of the complexity of 
stress-related issues regarding the processing of the optical fibers, the residual axial elastic stresses were implemented considering Equations (9) and (10) and the total resulting stress was obtained adding the thermally-induced residual stresses obtained with the program.

The implemented geometry consisted of a set of (concentric) cylinders with radius of curvatures accordingly with the characteristics of the core and cladding of the optical fiber described in the previous section. To avoid the influence of the external boundaries on the irradiated and analyzed zones, the overall length for the geometry was set as $11 \mathrm{~mm}$. However, to reduce the computational load and loosen the mesh dimensions in zones not affected by the irradiation, the cylinders were implemented as three separate sets; the central one, where the laser incidence will be simulated, has a $700 \mu \mathrm{m}$ length. Table 1 presents the 3D geometry data and the mesh statistics. Both outer boundary surfaces are defined as thermally isolated, being one of them fixed. The ambient temperature was considered to be $295 \mathrm{~K}$ and equal to the external temperature, $T_{\text {inf }}$ in Equation (4).

Table 1. Geometry data and mesh statistics.

\begin{tabular}{rccccc}
\hline & \multicolumn{2}{c}{ Central Geometry } & & \multicolumn{2}{c}{ External Geometries } \\
\cline { 2 - 3 } Cladding & Core & & Cladding & Core \\
\hline Geometry & & & & \\
Length $(\mathrm{mm})$ & 0.7 & 0.7 & & $5.15 \times 2$ & $5.15 \times 2$ \\
Radius $(\mu \mathrm{m})$ & 62.5 & 4.1 & & 62.5 & 4.1 \\
\hline Mesh (tetrahedral) & & & & \\
\# elements & 24,122 & 1,231 & & 27,917 & 1,704 \\
min. quality & 0.0474 & 0.1357 & & 0.2347 & 0.2017 \\
volume ratio & $9.46 \times 10^{-4}$ & 0.0934 & & 0.0019 & 0.4914 \\
\hline
\end{tabular}

\section{Experimental Methodologies}

The experimental procedure was based on a simple point-by-point laser writing on the fiber characterized previously. The fiber was periodically moved (500 $\mu \mathrm{m} \pm 1 \mu \mathrm{m}$ grating period) along its axial direction with a linear translation stage (Thorlabs NRT100) and periodically irradiated $(0.6 \mathrm{~s} \pm 5 \mu \mathrm{s}$ emission duration) by the beam emitted by a CW MIR $\mathrm{CO}_{2}$ laser source (Synrad 48-2); the maximum available power was $25 \mathrm{~W}$.

A schematic and a photograph of the set-up are shown in Figure 5 . A $50 \mathrm{~mm}$ focal length cylindrical lens focuses the initial $1.75 \mathrm{~mm}$ laser beam into a $0.15 \mathrm{~mm} \times 1.75 \mathrm{~mm}\left(r_{x} \times r_{y}\right)$ elliptical beam on the optical fiber. The dimensions of the beam on focus were measured through the knife-edge method, with an expected measurement error of $\pm 5 \mu \mathrm{m}$ [33].

In order to induce a constant strain to the fiber, a small weight (usually, several tenths of gram) is attached on one of the sides of the fiber, suspended. A broad band light source (Thorlabs S5FC1005S) and an optical spectrum analyzer (OSA, Agilent 86140B) allows monitoring the LPFG fabrication, while a fast camera (PCO SensiCAM), perpendicular to the irradiation axis, was used to optically visualize the process. The irradiated zones were analyzed through an optical microscope (Zeiss AxioScope A1) with maximum amplification of $1,000 \times$. 
Figure 5. (a) Schematic and (b) photograph of the setup used for $\mathrm{CO}_{2}$ laser writing a LPFG on a Corning SMF-28 fiber.

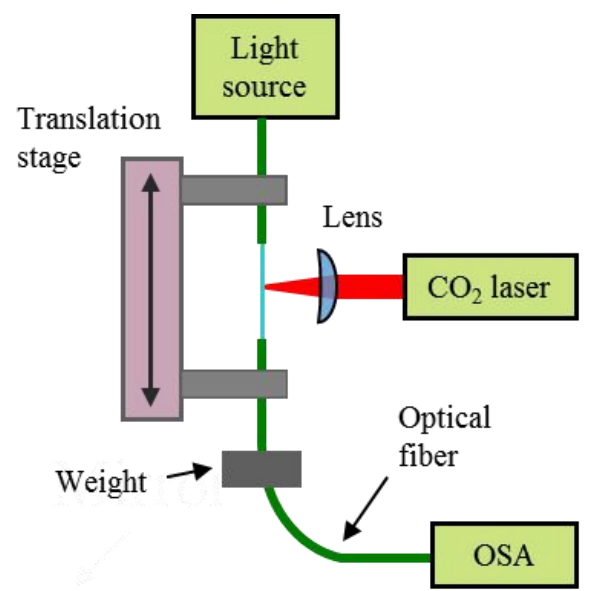

(a)

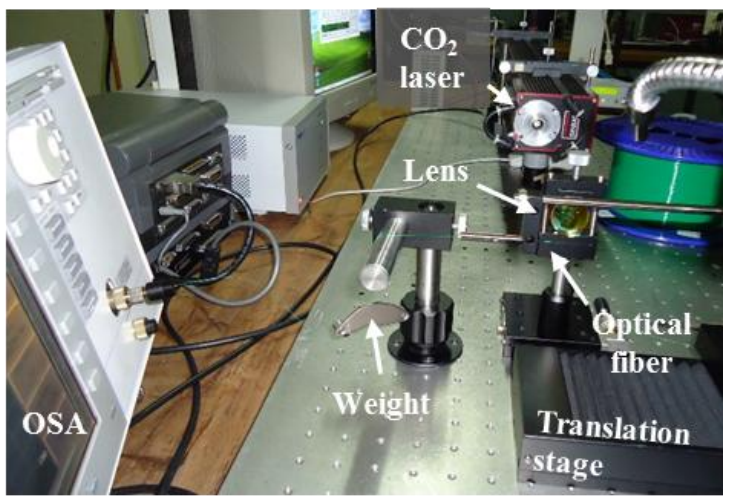

(b)

\section{Results and Analysis}

An example of the temperature distribution is shown in Figure 6, including a zoom view of the irradiated zone, for $6 \mathrm{~W}( \pm 0.5 \mathrm{~W})$ laser power, duration of $0.6 \mathrm{~s}( \pm 1 \mathrm{~ms})$ and $47 \mathrm{~g}( \pm 0.5 \mathrm{~g})$ weight $(F=0.461 \mathrm{~N})$, the base parameters for this study, taking in consideration the experimental results.

Figure 6. Temperature distribution in the implemented $3 \mathrm{D}$ geometry for the laser irradiation of an optical fiber $(P=6 \mathrm{~W} ; \tau=0.6 \mathrm{~s} ; F=0.461 \mathrm{~N})$. Color bar values are in $\mathrm{K}$.

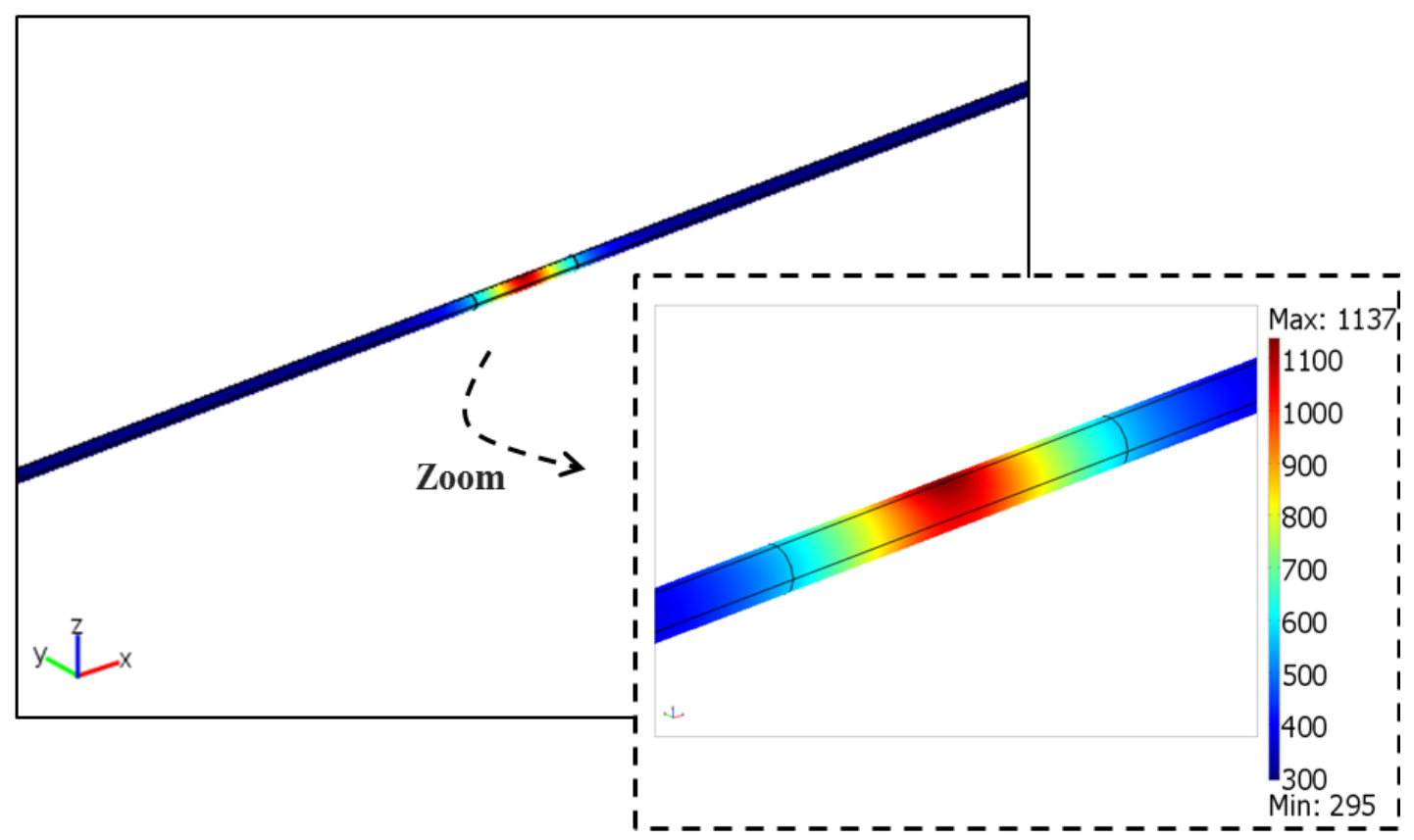

Figure 7 shows the plots resulting from the simulation using Equation (5) under the conditions mentioned before for the irradiated front surface, core/cladding interfaces (upper and lower) and the back surface of the fiber (Figure 1), and $x=y=0 \mathrm{~m}$. In Figure 7a, the duration of the simulation was 
made larger than the laser emission duration in order to visualize the cooling process. The plot in Figure $7 \mathrm{~b}$, representing the variation of temperature along the fiber's axial direction, shows that the temperature was slightly larger than $1,050 \mathrm{~K}$ at the interfaces between the core and cladding, and one could assume that the core could be considered as being at the same temperature. This assumption cannot hold for the cladding since its temperature varied about $100 \mathrm{~K}$ along its thickness.

Figure 7. Plots of the temperature (a) evolution during laser irradiation and cooling and (b) distribution at the fiber's axial direction simulated for $t=0.6 \mathrm{~s} .(P=6 \mathrm{~W} ; F=0.461 \mathrm{~N})$.

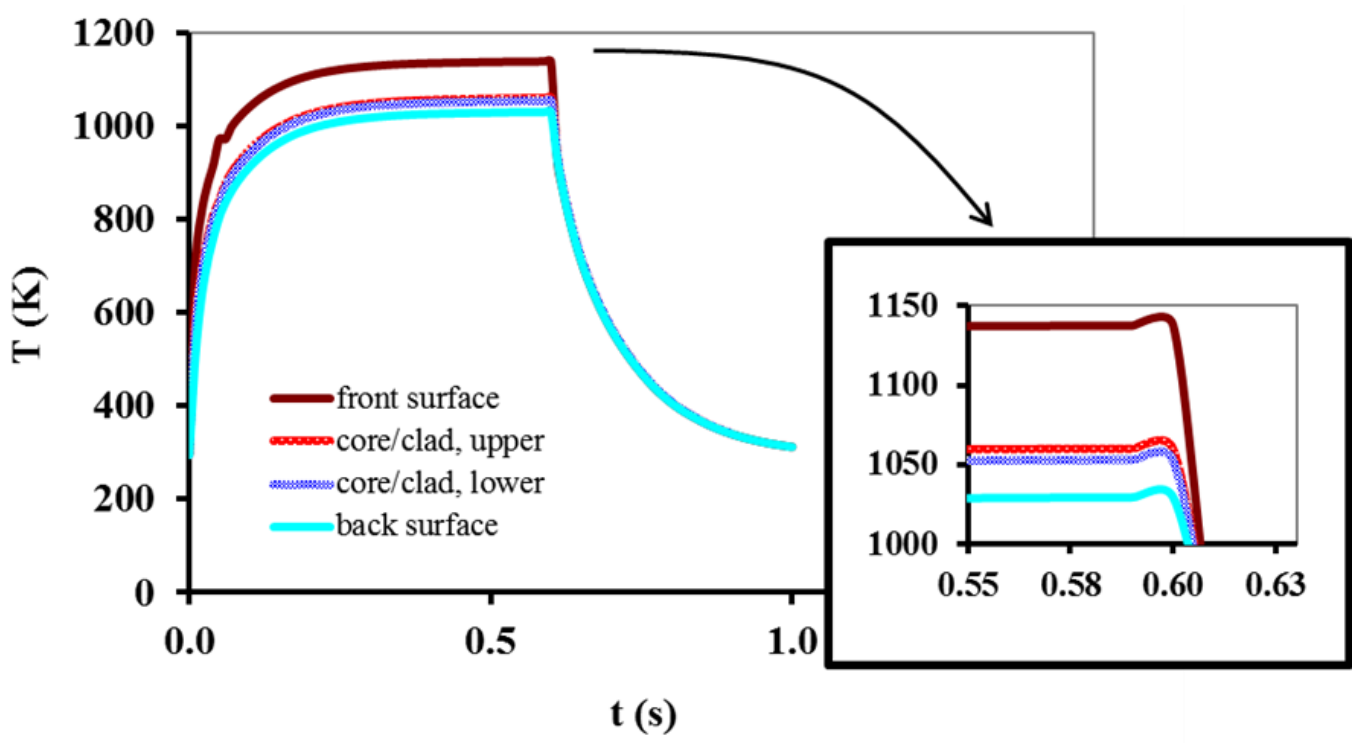

(a)

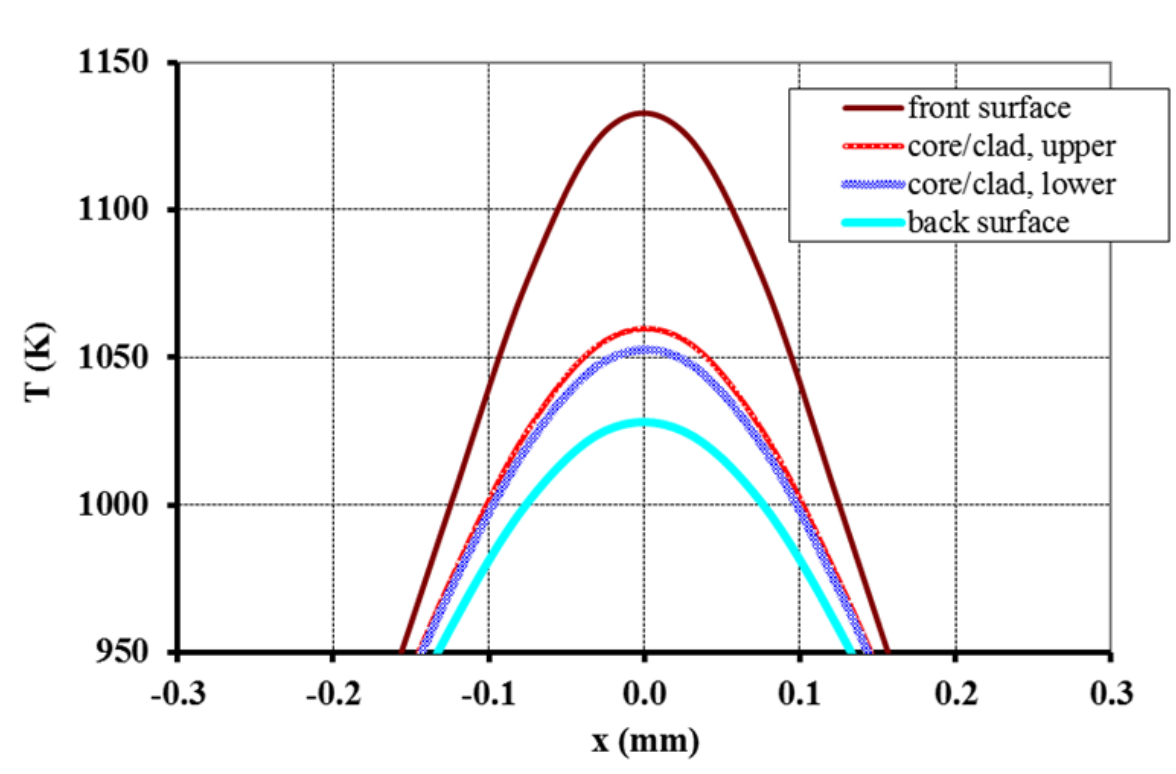

(b)

As the laser power increases, the temperature increases. Figure 8 shows the variation of temperature at the upper surface (at $x=y=0 \mathrm{~m}$ ) of the optical fiber with laser power as obtained from the model. 
For the considered example, at $t=0.6 \mathrm{~s}$, axial residual thermal stresses values along $\mathrm{z}$-axis were determined as having a maximum of about $-0.8 \mathrm{MPa}$. Axial elastic stresses act in the opposite direction and were calculated as being $\sigma_{x, c o}=35 \mathrm{MPa}$ and $\sigma_{x, c l}=0.153 \mathrm{MPa}$. The resulting refractive index change (the difference between final and initial values) is calculated to be in the order of $-2 \times 10^{-4}$ for the core and $4 \times 10^{-6}$ for the cladding. The refractive index distribution in the fiber (along the $z$-axis), before and after the laser irradiation is showed in Figure 9a and the maximum refractive index change (core and cladding) for different draw forces is plotted in Figure 9b. Figure 10 shows the calculated (maximum) refractive index change at the core and cladding for different laser power. Under the considered conditions, even if the refractive index of the core shows minor changes by increasing the laser power, it is possible to observe the beginning of the contribution of thermal stresses around $5 \mathrm{~W}$. This is clearly observed regarding the refractive index change for the cladding, where a well-defined step occurs between $4.5 \mathrm{~W}$ and $5 \mathrm{~W}$.

Figure 8. Plot of temperature variation with incident laser power simulated at $x=y=z=0 \mathrm{~m}$. $(\tau=0.6 \mathrm{~s} ; F=0.461 \mathrm{~N})$.

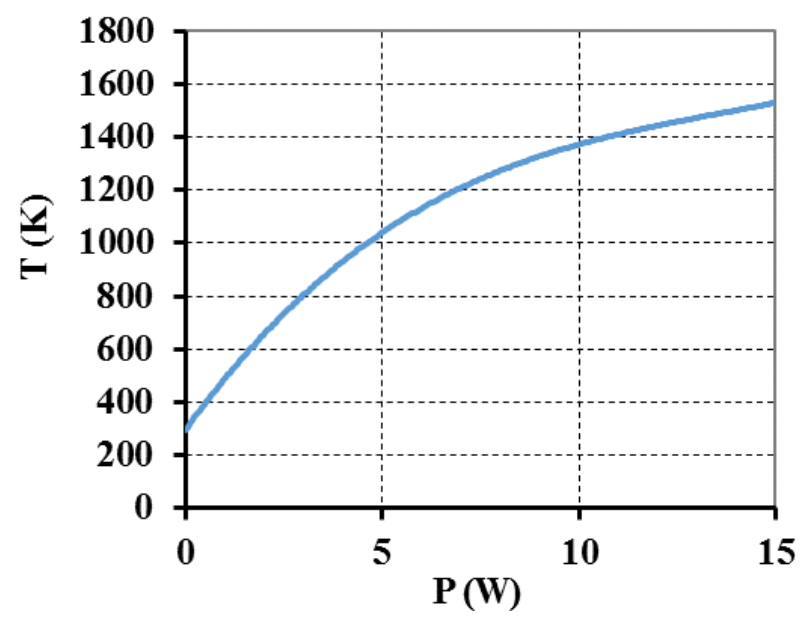

Figure 9. Calculated (a) refractive index profiles of the fiber, before and after laser irradiation $(F=0.461 \mathrm{~N})$; and $(\mathbf{b})$ refractive index change (maximum change for core and cladding) for different applied draw tensions. $(P=6 \mathrm{~W} ; \tau=0.6 \mathrm{~s})$.

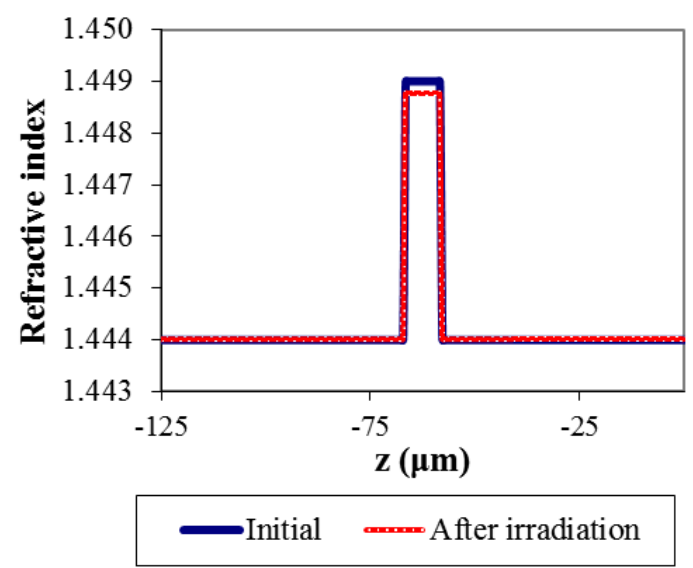

(a)

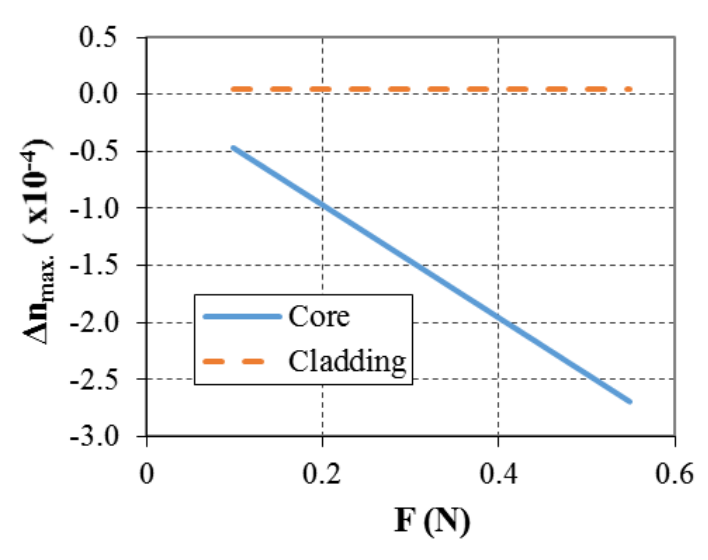

(b) 
Figure 10. Calculated (maximum) refractive index change at the (a) core and (b) cladding for different applied laser powers. $(\tau=0.6 \mathrm{~s} ; \mathrm{F}=0.461 \mathrm{~N})$.

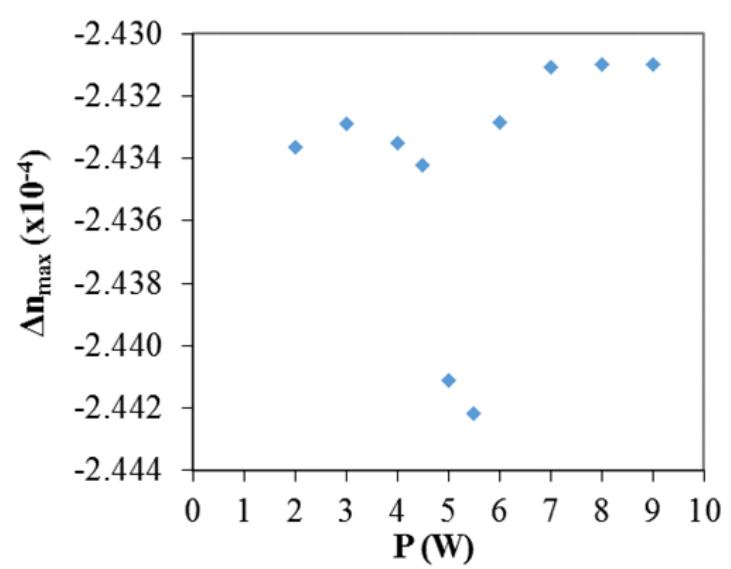

(a)

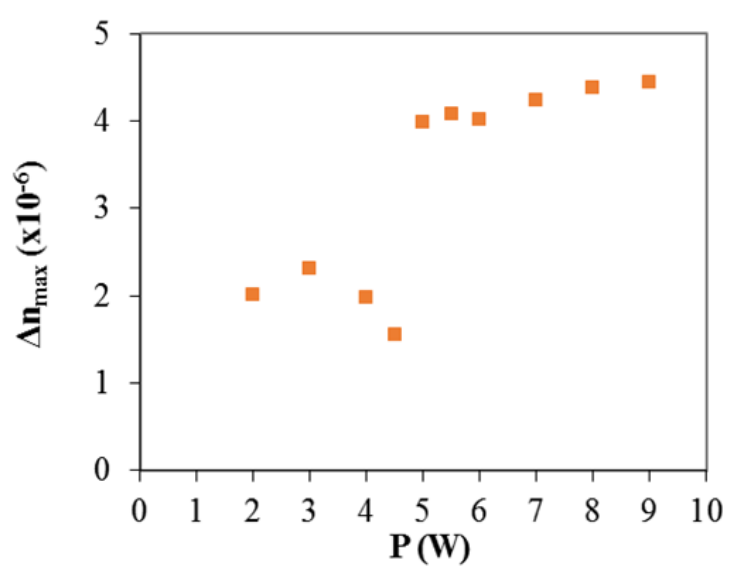

(b)

Figure 11a shows a microscope photograph of an irradiated fiber under the conditions considered in this work. The imaged zone was part of a $25-\mathrm{mm}$ grating with a period of $500 \mu \mathrm{m}$, and the visible affected area along the fiber's axis was about $130 \mu \mathrm{m}$ (supported on several measurements along the grating). Also visible was a (small) micrometric deformation of the fiber. Figure 11b shows the spectral transmission of the resultant LPFG, comparing the experimental data with the simulated spectrum. The latter was obtained using the refractive index changes obtained by the FEM model (and mentioned before) and using a simulation tool developed by Baptista [34] based on the three layer model developed by Erdogran [35,36].

Figure 11. (a) Picture showing an irradiated zone from a $25 \mathrm{~mm}$ LPFG with $500 \mu \mathrm{m}$ period and (b) experimentally obtained and simulated relative normalized spectral transmission. $(P=6 \mathrm{~W} ; \tau=0.6 \mathrm{~s} ; F=0.461 \mathrm{~N})$.

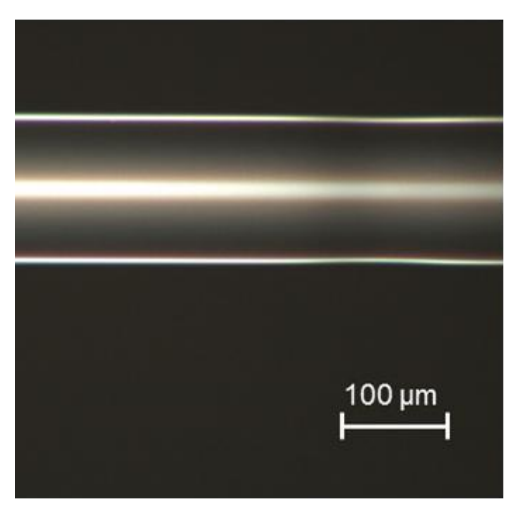

(a)

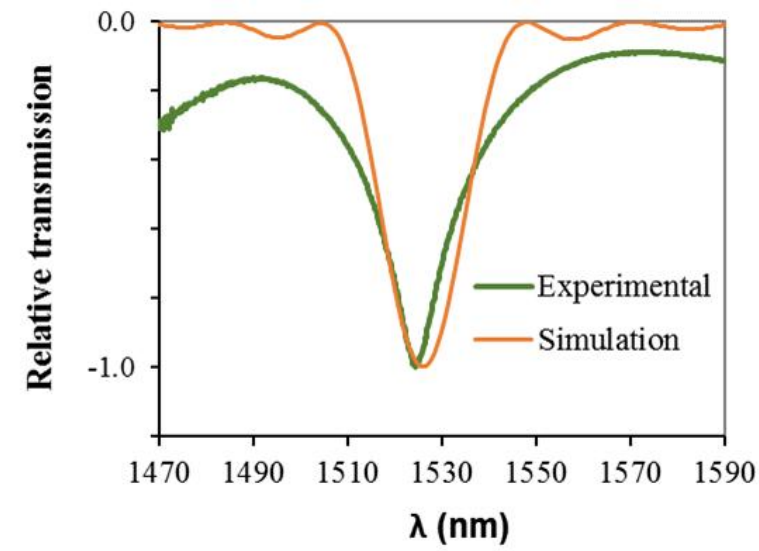

(b)

Analyzing both theoretical and experimental data, besides the relative spectral transmission data agreement, one can consider that it is necessary to reach temperatures higher than $1,000 \mathrm{~K}$ to accomplish an LPFG under these conditions. This assumption relies on the cross-analysis between the visible affected length of the fiber (around $130 \mu \mathrm{m}$ ) and the fiber's back surface temperature for $x=-65 \mu \mathrm{m}$ or $x=65 \mu \mathrm{m}$. This is in accordance with experimental evidences that, even for higher 
power conditions for which tapering occurs, the laser focal dimension influence on the affected volume prevail, at least at the surface [37].

Also, although we simulated the impact of different laser powers and weights, experimentally, using lower laser powers (typically $<5 \mathrm{~W}$ ) no LPFGs were obtained. For higher laser powers (typically $>8 \mathrm{~W}$ ) or higher weights (typically $>60 \mathrm{~g}, F>0.588 \mathrm{~N}$ ) tapering occurs, a phenomena not included in the developed model. These experimental observations can also be inferred from results obtained in the FEM model, based on the analysis of the plots shown in Figure 10, in particular regarding Figure 10b. In the latter case, and based on the analysis previously made, it is easily identified the required minimum applied power (5W) for writing LPFG under the considered conditions.

The values obtained by the model are also in agreement with those estimated by other authors for the refractive index modulations necessary for achieving a fiber optic grating. Temperatures obtained by the model are similar to those obtained by other authors for arc-induced LPFG (e.g., in the range $1,100 \mathrm{~K}-1,400 \mathrm{~K}$ according to [27]) and the refractive index changes obtained are also within the overall range mentioned (in the order of magnitude of $10^{-4}$ for the core and $10^{-6}$ for the cladding) in other works [17,19-21,27]. The obtained behavior of the refractive index change as the applied drawing force increases complies with the most recent experimental indications that the refractive index of the core decreases while the opposite occurs in the cladding, and that this change occurs primarily in the core $[20,21]$.

Nevertheless, due to the complexity of the physical phenomena involved, refractive index change dependence on stress also requires further research. Future work should focus on experimental measurements of temperature, stresses and refractive index changes induced by laser radiation. Although published works can contribute in assessing the validity of the results, the influence of specific characteristics of the fibers is a well-recognized issue. In particular, the effect of pre-existing stresses (e.g., from the fiber manufacture), differences in the materials, or other unaccounted phenomena can influence the performance of the FEM model when compared with real data. Similarly, the influence of the experimental data uncertainties on the model must be analyzed in detail, as well as the impact of the several approximations considered (e.g., transverse stresses are neglected), unaccounted phenomena like eventual changes on the glass polarizability and using standard material data.

\section{Conclusions}

The FEM model presented in this work demonstrated its potential to simulate the thermo-mechanical processes involved in writing LPFGs using $\mathrm{CO}_{2}$ laser radiation. It takes in account the influence of temperature on the most relevant thermal and mechanical parameters of the fiber material, as well as convective and radiative effects. The model is $3 \mathrm{D}$, considers a focused laser line irradiating a single-mode fiber for a given duration, and generates temperature and residual stresses distributions and the required refractive index change. An example of irradiating a single-mode optical fiber was presented and both theoretical (simulated) and experimental data are analyzed. Although additional work should be performed to further validate the analysis done (mainly regarding stresses acting in the optical fiber), the FEM results are in accordance with literature and experimental data. 


\section{Acknowledgments}

This work was partially supported by FEDER funding through the Programa Operacional Factores de Competitividade-COMPETE and by national funding by the FCT-Portuguese Fundação para a Ciência e Tecnologia through the project PTDC/FIS/119027/2010. The authors gratefully acknowledge José Luis Santos, Orlando Frazão and Pedro Jorge from INESC-Porto and Catarina Silva and D. Castro Alves for their advices and contributions. A special thanks to Fernando Monteiro and António Oliveira for their technical support to the activities described in this paper.

\section{Conflict of Interest}

The authors declare no conflict of interest.

\section{References}

1. Patrick, H.; Chang, C.; Vohra, S. Long period fiber gratings for structural bending sensing. Electron. Lett. 1998, 34, 1773-1775.

2. Bhatia, V. Applications of long-period gratings to single and multi-parameter sensing. Opt. Express 1999, 4, 457-466.

3. Falciai, R.; Mignani, A.; Vannini, A. Long period gratings as solution concentration sensors. Sens. Actuators B Chem. 2001, 74, 74-77.

4. James, S.; Tatam, R. Optical fibre long-period grating sensors: Characteristics and application. Meas. Sci. Technol. 2003, 14, R49-R61.

5. Chen, G.; Xiao, H.; Huang, Y.; Zhou, Z.; Zhang, Y.A. Novel long-period fiber grating optical sensor for large strain measurement. Proc. SPIE 2009, 7292, 729212.

6. Wang, J.; Tang, J.-L. Feasibility of fiber bragg grating and long-period fiber grating sensors under different environmental conditions. Sensors 2010, 10, 10105-10127.

7. Silva, C.; Coelho, J.M.P.; Caldas, P.; Jorge, P. Fiber Sensing System Based on Long-Period Gratings for Monitoring Aqueous Environments. In Fiber Optic Sensors; Yasin, M., Harun, S., Arof, H., Eds.; InTech: Ridjeka, Croatia, 2012; pp. 317-341.

8. Kersey, A.D.; Davis, M.A.; Heather, J.P.; LeBlanc, M.; Koo, K.P.; Askins, C.G.; Putnam, M.A.; Friebele, E.J. Fiber grating sensors. J. Lightwave Technol. 1997, 15, 1442-14463.

9. Savin, S.; Digonnet, M.J.F.; Kino, G.S.; Shaw, H.J. Tunable mechanically induced long-period fiber gratings. Opt. Lett. 2000, 25, 710-712.

10. Vaziri, M.; Che, C.L. An etched two-mode fiber modal coupling element. J. Lightwave Technol. 1997, 15, 474-481.

11. Vengsarkar, A.M.; Lemaire, P.J.; Judkins, J.B.; Bhatia, V.; Erdogan, T.; Sipe, J.E. Long-period fiber gratings as band-rejection filters. J. Lightwave Technol. 1996, 14, 58-65.

12. Estudillo-Ayala, J.; Mata-Chavez, R.; Hernandez-Garcia, J.; Rojas-Laguna, R. Long Period Fiber Grating Produced by Arc Discharges. In Fiber Optic Sensors; Yasin, M., Harun, S., Arof, H., Eds.; InTech: Ridjeka, Croatia, 2012; pp. 295-316. 
13. Davis, D.D.; Gaylord, T.K.; Glytis, E.N.; Kosinski, S.G.; Mettler, S.C.; Vengsarkar, A.M. Long period fiber grating fabrication with focused $\mathrm{CO}_{2}$ laser pulses. Electron. Lett. 1998, 34, 302-303.

14. Akiyama, M.; Nishide, K.; Shima, K.; Wada, A.; Yamauchi, R. A Novel Long-Period Fiber Grating Using Periodically Releases Residual Stress of Pure-Silica Core Fiber. In Proceedings of the Optical Fiber Communication Conference (OFC), San José, CA, USA, 22-27 February 2008; pp. 276-277.

15. Coelho, J.M.P.; Nespereira, M.; Silva, C.; Pereira, D.; Rebordão, J.M. Advances in Optical Fiber Laser Micromachining for Sensors Development. In Current Developments in Optical Fiber Technology; Harun, W., Arof, H., Eds.; InTech: Rijeka, Croatia, 2013; pp. 375-401.

16. Yablon, A.D. Optical and mechanical effects of frozen-in stresses and strains in optical fibers. IEEE J. Sel. Topics Quantum Electron. 2004, 10, 300-311.

17. Yablon, A.D.; Yan, M.F.; Wisk, P.; DiMarcello, F.V.; Fleming, J.W.; Reed, W.A.; Monberg, E.M.; DiGiovanni, D.J.; Jasapara, J. Refractive index perturbations in optical fibers resulting from frozen-in viscoelasticity. Appl. Phys. Lett. 2004, 84, 19-21.

18. Lancry, M.; Réginier, E.; Poumellec, B. Fictive temperature in silica-based glasses and its application to optical fiber manufacturing. Progr. Mater. Sci. 2012, 57, 63-94.

19. Kim, B.H.; Ahn, T.-J.; Kim, D.Y.; Lee, B.H.; Chung, Y.; Paek, U.-C.; Han, W.-T. Effect of $\mathrm{CO}_{2}$ laser irradiation on the refractive-index change in optical fibers. Appl. Opt. 2002, 41, 3809-3815.

20. Li, Y.; Wei, T.; Montoya, J.A.; Saini, S.V.; Lan, X.; Tang, X.; Dong, J.; Xiao, H. Measurement of $\mathrm{CO}_{2}$-laser-irradiation-induced refractive index modulation in single-mode fiber toward long-period fiber grating design and fabrication. Appl. Opt. 2008, 47, 5296-5304.

21. Hutsel, M.R.; Gaylord, T.K. Residual-stress relaxation and densification in $\mathrm{CO}_{2}$-laser-induced long-period fiber gratings. Appl. Opt. 2012, 51, 6179-6187.

22. Grellier, A.J.C.; Zayer, N.K.; Pannell, C.V. Heat transfer modelling in $\mathrm{CO}_{2}$ laser processing of optical fibres. Opt. Commun. 1998, 152, 324-328.

23. Coelho, J.M.P.; Nespereira, M.C; Abreu, M.; Rebordão, J.M. Modeling refractive index change in writing long-period fiber gratings using mid-infrared laser radiation. Photonic Sens. 2012, 2, 1-7.

24. Coelho, J.M.P.; Abreu, M.A.; Carvalho-Rodrigues, F. Modelling the spot shape influence on high-speed transmission lap welding of thermoplastics films. J. Opt. Lasers Eng. 2008, 46, 55-61.

25. Kong, F.; Kovacevic, R. 3D finite element modeling of the thermally induced residual stress in the hybrid laser/arc welding of lap joint. J. Mater. Process. Technol. 2010, 210, 941-950.

26. Timoshenko, S.P.; Goodier, J.N. Theory of Elasticity, 2nd ed.; McGraw-Hill: New York, NY, USA, 1951; pp. 409-410.

27. Rego, G.M. Arc-Induced Long-Period Fibre Gratings. Fabrication and Their Application in Communications and Sensing. Ph.D. Thesis, Department Electrical Computer Engineering, University of Porto, Porto, Portugal, 17 July 2006.

28. Corning Inc. Corning ${ }^{\circledR}$ SMF-28 Optical Fiber Product Information, 2002. Available online: http://www.corning.com/WorkArea/showcontent.aspx?id=41261 (accessed on 16 June 2013).

29. André, P.; Rocha, A.; Domingues, F.; Facão, M. Thermal Effects in Optical Fibers. In Developments in Heat Transfer; Bernardes, M.A.S., Ed.; InTech: Ridjeka, Croatia, 2011; pp. 1-20.

30. Clowes, J.; Syngellakis, S.; Zervas, M. Pressure sensitivity of side-hole optical fiber sensors. IEEE Photon. Technol. Lett. 2009, 10, 857-859. 
31. Yang, S.; Matthews, M.; Elhadj, S.; Draggoo, V.; Bisson, S. Thermal transport in $\mathrm{CO}_{2}$ laser irradiated fused silica: In situ measurements and analysis. J. Appl. Phys. 2009, 106, doi:10.1063/1.3259419.

32. McLachlan, A.; Meyer, F. Temperature dependence of the extinction coefficient of fused silica for $\mathrm{CO}_{2}$ laser wavelengths. Appl. Opt. 1987, 26, 1728-1731.

33. Siegman, A.E.; Sasnett, M.W.; Johnston, T.F. Choice of clip level for beam width measurements using knife-edge techniques. IEEE J. Quantum Electron. 1991, 27, 1098-1104.

34. Baptista, F.D.V. Simulação do Comportamento Espectral de Redes de Período Longo em Fibra Óptica. M.Sc. Thesis, Centro de Ciências Exactas e da Engenharia, University of Madeira: Funchal, Portugal, November 2009.

35. Erdogan, T. Cladding-mode resonances in short- and long-period fiber grating filters. J. Opt. Soc. Am. A 1997, 14, 1760-1773.

36. Erdogan, T. Cladding-mode resonances in short- and long-period fiber grating filters: Errata. J. Opt. Soc. Am. A 2000, 17, doi:10.1364/JOSAA.17.002113.

37. Nespereira, M.; Coelho, J.M.P.; Monteiro, F.; Abreu, M.; Rebordão, J.M. Optical fiber tapers produced by near-infrared laser radiation. Proc. SPIE 2013, 8785.

(C) 2013 by the authors; licensee MDPI, Basel, Switzerland. This article is an open access article distributed under the terms and conditions of the Creative Commons Attribution license (http://creativecommons.org/licenses/by/3.0/). 